This article was downloaded by: [The University of Manchester]

On: 24 May 2010

Access details: Access Details: [subscription number 915545543]

Publisher Psychology Press

Informa Ltd Registered in England and Wales Registered Number: 1072954 Registered office: Mortimer House, 3741 Mortimer Street, London W1T 3JH, UK

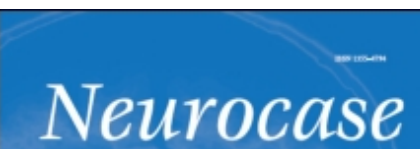

The Neural Basis of Cognition

\title{
Neurocase
}

Publication details, including instructions for authors and subscription information:

http://www.informaworld.com/smpp/title content=t713658146

\section{Life in a mirrored world: Report of a case showing mirror reversal in reading and writing and for non-verbal materials}

Matthew A. Lambon-ralph ${ }^{\text {a }}$; Carrie Jarvis ${ }^{b}$;Andrew W. Ellis ${ }^{c}$

${ }^{a}$ MRC Applied Psychology Unit, Cambridge ${ }^{b}$ General Department of Speech and Language Therapy, Ashington Hospital, Sunderland ${ }^{\mathrm{c}}$ Department of Psychology, University of York, York, UK

To cite this Article Lambon-ralph, Matthew A. , Jarvis, Carrie andEllis, Andrew W.(1997) 'Life in a mirrored world: Report of a case showing mirror reversal in reading and writing and for non-verbal materials', Neurocase, 3: 4, $249-258$

To link to this Article: DOI: $10.1080 / 13554799708405008$

URL: http://dx.doi.org/10.1080/13554799708405008

\section{PLEASE SCROLL DOWN FOR ARTICLE}

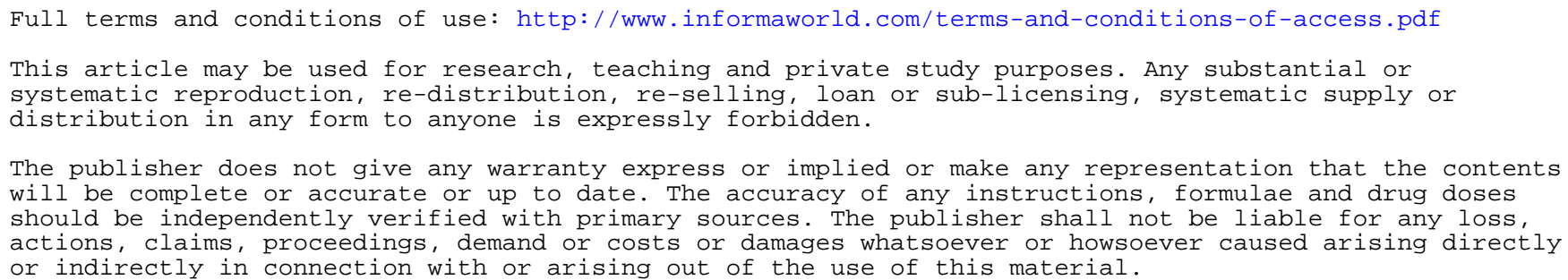




\title{
Life in a Mirrored World: Report of a Case Showing Mirror Reversal in Reading and Writing and for Non-verbal Materials
}

\author{
Matthew A. Lambon-Ralph, Carrie Jarvis' ${ }^{1}$ and Andrew W. Ellis ${ }^{2}$ \\ MRC Applied Psychology Unit, 15 Chaucer Road, Cambridge CB2 2EF, 'General Department of Speech and Language Therapy, \\ Ashington Hospital, Sunderland SR4 7TP and ${ }^{2}$ Department of Psychology, University of York, York YO1 5DD, UK
}

\begin{abstract}
We report a single case study of a patient 'Allce' who, following a series of ischaemic attacks, became a mirror reader and mirror writer. Alice read mirror-reversed words much more efficiently than conventionally presented items. Additional tests revealed a mirror reversal of many non-verbal, spatial representations including clock faces, geometric figures and country outlines. Although Alice showed more efflcient right-left than left-right scanning, this scanning bias was not able to account for all her mirror symptoms. Possible theoretical Interpretations of Alice's pattern of symptoms are discussed.
\end{abstract}

\section{Introduction}

The neuropsychological literature contains accounts of a variety of what might be termed 'mirror phenomena'. Perhaps the best known of these is "mirror writing', where the patient writes from right to left using mirror-reversed letters, often with the non-preferred hand, following damage affecting the dominant hemisphere (Critchley, 1928; Ellis, 1988; Rodríguez et al., 1989). The result is writing which can only be read easily by either viewing it in a mirror or holding the page up to the light and reading it through the paper. In most cases, this is what the patients themselves have to do if they want to re-read their own handwriting at a later date: most mirror writers find mirror reading as difficult as normal writers do (Corballis and Beale, 1976, 1983; Critchley, 1928). Theoretical accounts of mirror writing which seem capable of explaining most occurrences propose that, following brain injury, the left hand is controlled by motor programmes appropriate for the right hand (cf. Buxbaum et al., 1993; Chan and Ross, 1988).

A different phenomenon was first described by Bramwell (1909) who noted the case of HT, a young, left-handed boy who suffered from occasional epileptic seizures. From the time he began to learn to read, he read everything backwards, for example, reading GOD as 'dog'. This tendency was not overcome until HT was about 7 years old.
Bramwell called this 'mirror reading', but it did not involve a proficiency at reading mirror-reversed text. Rather it seems to have involved a strong bias. towards right-to-left scanning of letters and words which were then read in reversed order. Hence we would suggest that this type of reading should be called 'reverse reading', preserving the term 'mirror reading' for a different phenomenon to be reported below. (Bramwell also states that HT showed 'mirror writing', but it is not clear whether by this he means using mirror-reversed letters or writing the letters of words in reverse order.)

A case somewhat similar to Bramwell's was reported a few years later by Downey (1914). She studied in some detail the reading and writing of a 25-year-old college student, referred to simply as $\mathrm{X}$, who reported 'a longcontinued habit' of mirror writing and reading. $X$ showed (right-handed) mirror writing as a child. She was eventually taught to write normally, but said that she sometimes reverted to mirror writing when she was tired. What Downey called her 'mirror reading' once again involved a strong tendency to read the words on a line of ordinary text from right to left (i.e. reverse reading). $X$ was no better at reading mirror-reversed script than some of the other students in her class. That said, $X$ discovered that she had a natural proficiency for typesetting (in which 
mirror-reversed letters must be laid out in reverse order so that they appear in the correct fashion when printed). $\mathrm{X}$ commented, "Within a month I could set type as fast as my cousin could, although he had worked at this ten or more years' (p. 409).

Streifler and Hofman (1976) described a 47-year-old business woman with 'slight brain concussion' who found herself unable to read her first learnt script, Hebrew, which is written right to left. She continued, however, to be able to read German and her native Polish, both of which are written left to right. Hebrew script could be deciphered only if it was presented as mirror-reversed letters running either left-to-right or down the page. If the letters were presented to the patient in reversed order but in normal orientation, she was still unable to read the Hebrew words. She could still write her name in Latin script, as in German or Polish, but produced mirror writing when asked to write Hebrew. Unlike the previous cases, the bias in this patient favoured left to right rather than right to left directions in both writing and reading. Also, her condition was an acquired rather than a developmental one. She also showed right-left disorientation and spatial confusion in some nonverbal tasks. Thus, Streifler and Hofman (1976) noted that on her return home from hospital, the patient complained that everything seemed to be reversed: "At first I thought they had prepared a surprise for me and had changed everything' (p. 360).

Heilman et al.'s (1980) left-handed patient mirror wrote and showed reverse reading (e.g. Where is it? $\rightarrow$ 'It is where?'; Write your name $\rightarrow$ 'Name your write'). He also read some individual words backwards (e.g. saw $\rightarrow$ 'was'; pen $\rightarrow$ 'nep'). Of particular interest is that this patient showed left-right confusion in some non-verbal tasks. For example, when asked to indicate on a drawing of a baseball field the direction in which he would run the bases, he drew his course in a clockwise (reversed) direction. He labelled the numbers on an old-style, circular telephone dial in reverse order and had difficulty indicating which side of the road he would drive on. In contrast, he drew a map of Florida in the correct orientation, and selected the correct outline when given the choice between it and a mirrorreversed one. He showed good understanding of left and right as applied to his own body, but was at chance in pointing to the examiner's left and right hands. The patient had a mild right hemiparesis but no lesion was visible on a brain scan and the patient's mirror writing and reverse reading had disappeared when he was seen again 3 months later.

Wade and Hart (1991) reported a 38-year-old, lefthanded patient with mild mental retardation and 12 years of special education who had suffered from generalized seizures from the age of five. MRI and CT scans were normal. She mirror wrote with her dominant left hand but produced normal script with her non-dominant right hand. When reading normal passages of text she showed a tendency towards reverse reading, identifying words starting at the right end of the line and working leftwards. Tactile recognition of mirror-reversed letters was faster than recognition of letters in their conventional forms, but visual recognition of mirrored letters seems not to have been tested. Like Heilman et al.'s (1980) patient, Wade and Hart's patient showed a degree of spatial confusion in nonverbal tasks. Again, she indicated the direction of play on a baseball field incorrectly and was confused over the direction of traffic on the road. She labelled the hot and cold taps for a sink incorrectly, and indeed complained that she frequently drank warm water by mistake. She could identify left and right on her own body but reversed right and left on the examiner's body.

Finally, we note that mirror phenomena can occur in the non-verbal domain in patients who show few if any problems with written language. Feinberg and Jones (1985) described a patient with a lesion in the region of the right angular gyrus who consistently reversed the orientation of everyday objects, for example putting the wrong end of his spoon in his coffee cup or lighting the wrong end of his cigarette. He substituted left for right in describing routes from place to place and chose mirror-imaged representations of New York State and the United States when given a choice between correct and mirrored versions. However, there was no mirror writing, and the only problem noted with reading was a tendency to confuse letters that are rotational variants of each other, such as ' $d$ ' and 'p'. Turnbull and McCarthy's (1996) patient RJ seemed unable to see the difference between pairs of objects that were mirror versions of each other, though he could easily discriminate objects that differed in other respects. However, although RJ could not tell the difference between a tiger facing leftward and a tiger facing rightward he discriminated normal from mirror-reversed words with a high degree of accuracy. RJ had bilateral parietal lobe infarctions.

We report here the case of a patient whom we shall call 'Alice'. Following a left hemisphere cerebrovascular accident and progressive ischaemia this patient presented with mirror writing and (genuine) mirror reading. She also showed mirror phenomena affecting non-verbal representations, combined with a degree of spatial disorientation.

\section{Case report}

At the time of testing Alice was a 42-year-old, right-handed woman. She was born in Australia in 1954 and received 10 years of standard education. She completed a 2-year diploma and had done 3 years of a 4-year B.Ed qualification when she suffered her first CVA (in 1992). She had been a member of Mensa, a society whose entry requirements include having an IQ of 140 or above. Unfortunately we know little about Alice's developmental history, particularly with regard to reading and writing. Prior to the first CVA, however, she had been a keen reader, and given the level of her academic achievement it seems most likely that her subsequent reading problems were acquired rather than 
representing a return to a previous (abnormal) developmental pattern. She had a complex medical history which included diabetes, obesity, being a regular smoker, hyperlipidaemia and persistent left retro-orbital headaches.

Following the CVA in 1992 Alice is described in her case notes as having a right hemiplegia, facial weakness and expressive dysphasia. Her speech was described as slow and deliberate with occasional word-finding difficulties, and she received a short course of speech and language therapy. She found reading very difficult, but no mirror phenomena were noted at the time. Although there was evidence of surface dysgraphia, Alice did not produce mirror writing.

Alice discovered her propensity for mirror reading quite by accident in 1994. As part of her occupational therapy Alice was asked one day to iron transfers onto T-shirts. When these are being applied, the writing on the transfers is mirror-reversed from the point of view of the person doing the ironing. To her surprise, Alice noticed that she could read the mirrored writing on the transfers with ease. At this point she was referred back for further assessment by speech and language therapists. Her right hemiplegia persisted, and a right hemianopia was also noted. (We assume that the hemianopia had been present since 1992, though it was not noted at that time.) Her speech was flat and aprosodic with some mild word-finding difficulties. By this time, Alice was reading text either via its reflection in a mirror or through the back of the page. Her mirror reading was now accompanied by mirror writing with her nondominant left hand.

Between 1992 and 1994 Alice suffered from progressive ischaemia which was monitored by a series of CT scans. A scan taken in 1992 revealed focal areas of acute infarction in the left basal ganglia and posterior temporal region, in the vascular territory of the left middle cerebral artery (see Fig. 1a). A scan in 1994 showed the established atrophy plus significant atrophy of the left temporalparietal region associated with dilation of the left lateral ventricle and cortical sulci (see Fig. 1b).

Our investigations were carried out between February and August 1996. The severe right hemiplegia and right hemianopia were still present. The word-finding difficulties evident in her conversation were confirmed by her performance on the Boston Naming Test (Kaplan et al., 1976) where she named $38 / 60$ items correctly, with semantic errors and circumlocutions as the predominant error types.

\section{Experimental investigations}

\section{Scanning non-verbal arrays}

Alice showed no apparent visuospatial neglect (right or left) on simple cancellation tasks. She did, however, show a marked scanning bias, finding it easier to scan right to left than left to right. This was confirmed using two simple tests. The first required her to join up a series of 11 numbered circles. The circles were $8 \mathrm{~mm}$ in diameter and were scattered within a rectangular area $16 \mathrm{~cm}$ by $7.5 \mathrm{~cm}$. Each circle contained a number within it, and the circles were numbered 1 to 11 in either left-to-right or right-to-left order. Alice's task was to join the circles in numerical order using a pen held in her left hand, which required her to move the pen in either a right-to-left or a left-to-right direction. She was much quicker to complete the task right to left $(14.1 \mathrm{~s})$ than left to right $(50.1 \mathrm{~s})$.

The previous task requires both visual scanning and movement, so the right-left bias could arise from either source. The second task required Alice to name 36 geometrical shapes arrayed in six lines of six shapes each. The shapes were approximately $1.8 \mathrm{~cm}$ in diameter and were spaced equidistantly in $30 \mathrm{~cm}$ lines on sheets of horizontal A3 paper. Alice was asked to name them in either left-toright or right-to-left order. Visual scanning is once more required, but the use of a verbal response eliminates (simple) motor biases. Alice was quicker to report the shapes in a right-to-left direction ( $1 \mathrm{~min} 13 \mathrm{~s})$ than in a leftto-right direction ( $1 \mathrm{~min} 53 \mathrm{~s}$ ).

\section{Mirror writing}

When writing for her own benefit, Alice found it easier to mirror write with her left hand than to write normally. She habitually wrote in upper-case letters (see Fig. 2). Alice could, however, write normally with her left hand when she needed to (e.g. when writing notes for other people), but she said that this was much harder. She reported finding it easier to re-read her own mirror writing than her conventional writing.

\section{Reading conventional and mirror-reversed words}

We have already noted that after her stroke in 1992 Alice found reading difficult, and she discovered her propensity for mirror reading in 1994. We cannot say for certain whether this propensity developed between 1992 and 1994, possibly in response to the additional ischaemic damage, or lay undiscovered from 1992 to the incident with the T-shirts in 1994.

In order to explore her mirror reading further, Alice was given a selection of reading tests in which letters or words were presented in either conventional or mirror-reversed form. Several of the lists were taken from the PALPA Battery (Kay et al., 1992). Where possible, both accuracy and reading times (measured by stop-watch) were collected. Alice was also given a lexical decision test from the PALPA where she was shown words or non-words one at a time and had to say whether each item was a word or not. The results are shown in Table 1.

Alice's general level of accuracy was high for both letters and words, showing no apparent difference between conventional and mirrored forms. Her reading times, in contrast, showed a marked advantage for mirrored over conventional letters and words. On every test where 
(a)

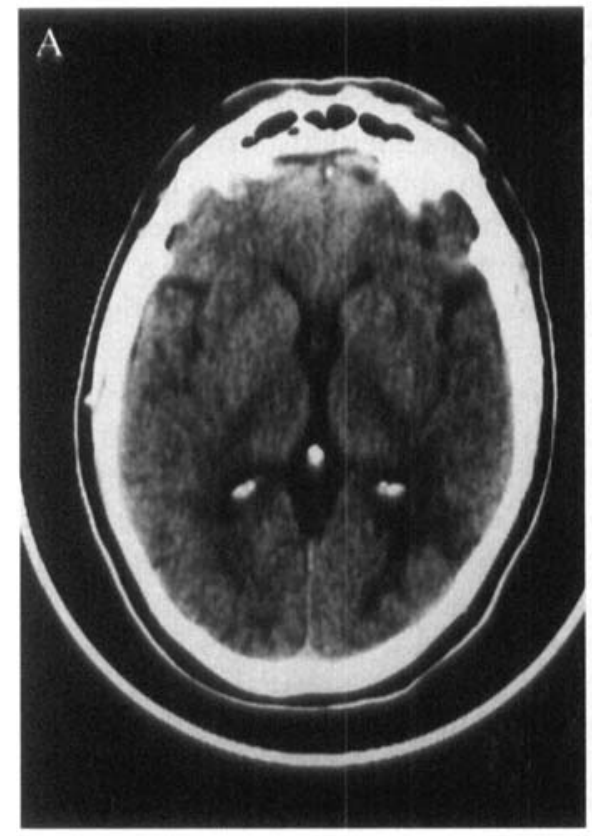

(b)

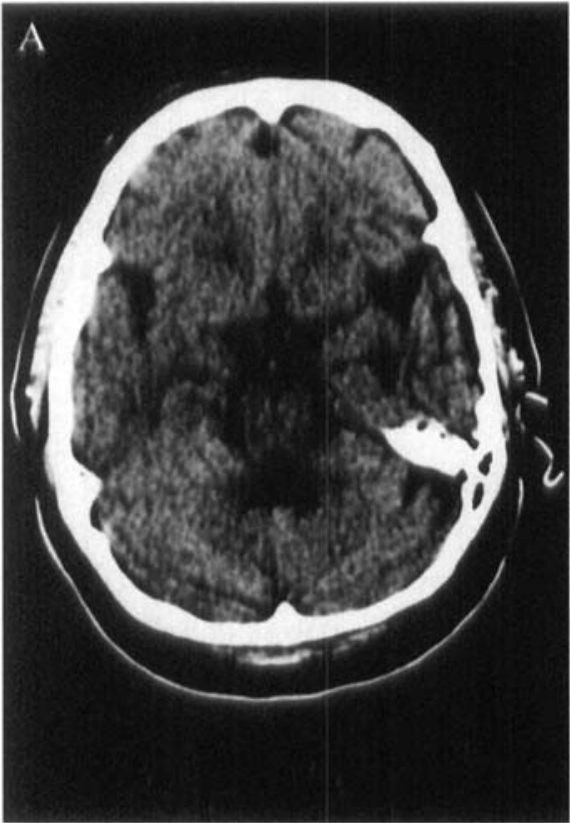

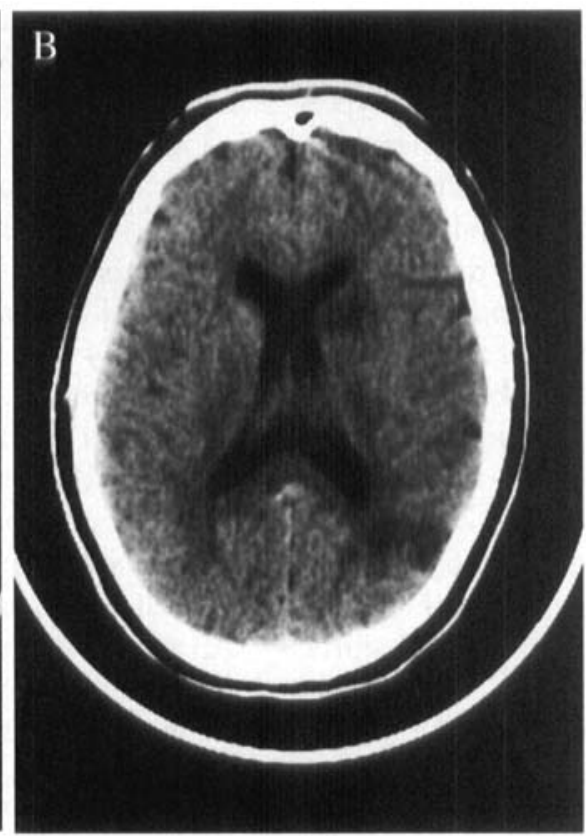
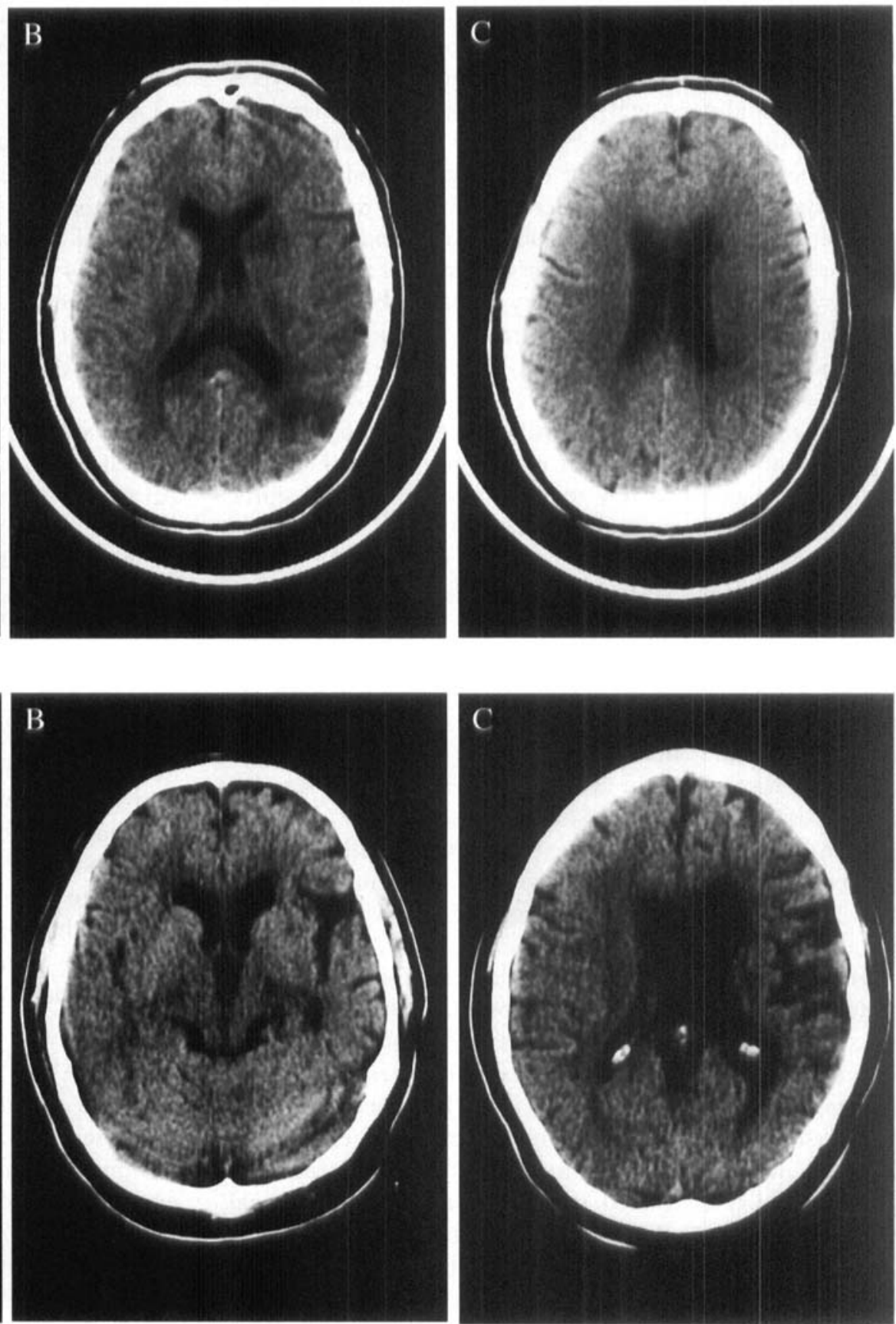

Fig. 1. (a) CT scan from 1992; (b) CT scan from 1994.

reaction times could be taken she was at least twice as fast reading mirrored forms as conventional forms. In fact, her performance on some tasks was too fast for accurate stopwatch timing. These included reading the short, reversible words in mirror format, where all her reading times were less than $1 \mathrm{~s}$, and lexical decision responses to mirrored words and non-words.

Four specific points are worthy of note. The first is that, unlike patients who showed reverse reading (e.g. Bramwell, 1909; Heilman et al., 1980), Alice never reversed the order of letters within a word. This was true even when she was presented with short, reversible words (e.g. GOD/DOG,
SAW/WAS). Second, on a test of reading aloud which varied the letter length of the target words (short: 3-4 letters versus long: 7-8 letters), with the words being matched pairwise for frequency (Kucera and Francis, 1967), imageability and age of acquisition (Quinlan, 1992), Alice was significantly faster to read short than long words for the conventional presentation $(t=4.6$, $P<0.001)$ but not the mirror-reversed condition $(t=0.78$, NS). This suggests that she was recognizing the component letters of mirrored words 'in parallel' but was employing a more serial strategy for words in conventional orientation, where her performance bore some 
Examples of Alice's mirror writung, written across and down the page.

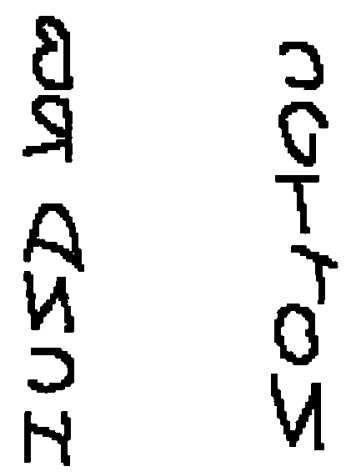

\section{HMAS8}

Alice's examples mirror-reversed
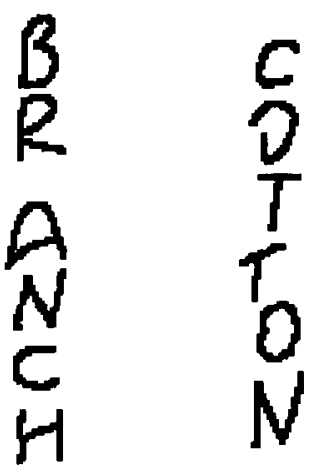

Fig. 2. An example of Alice's mirror writing with the normalized form for comparison.

resemblance to that of letter-by-letter readers (Howard, 1991). Third, Alice's superior performance in reading mirrored words was found for word recognition. She took much longer to complete the lexical decision task when presented in conventional type. Finally, the superiority of mirrored over conventional format for words that was observed in reading aloud and lexical decision extended to comprehension. In a test requiring her to indicate which of five pictures matched a centrally presented word, Alice was significantly quicker to identify the meaning of the mirrored items and point to the appropriate picture $(t=5.4, P<0.001)$.

\section{Distinguishing between mirror reversal and scanning direction in reading}

Mirrored words are read from right to left whereas conventional words are read from left to right. We have already seen that Alice showed better right-to-left than left-to-right scanning when joining numbered circles or reporting rows of shapes. The next set of tests were designed to assess the relative contributions of mirrored forms and scanning direction to her observed superior performance with mirrored over conventional words.
Examples of word formats used to assess the contribution of letter order (direction) and orientation on Alice's reading.

\begin{tabular}{|c|c|c|c|}
\hline Format & Letter Order (direction) & Letter Orientation & Example \\
\hline 1 & left $\rightarrow$ right & conventional & PAPER \\
\hline 2 & left $\rightarrow$ right & mirrored & ФАТНЯ \\
\hline 3 & right $\rightarrow$ left & conventional & REPAP \\
\hline 4 & right $\rightarrow$ left & mirrored & Я겸 \\
\hline 5 & top $\rightarrow$ bottom & conventional & $\begin{array}{l}\mathbf{P} \\
\mathbf{A} \\
\mathbf{P} \\
\mathbf{E} \\
\mathbf{R}\end{array}$ \\
\hline 6 & top $\rightarrow$ bottom & mirrored & $\begin{array}{c}\mathbf{q} \\
\mathrm{A} \\
\mathbf{q} \\
\mathbf{B} \\
\mathcal{Я}\end{array}$ \\
\hline
\end{tabular}

Fig. 3. Illustration of word formats used to distinguish letter orientation from letter order in reading.

Twenty words in upper-case letters were given to Alice to read in four different formats on four different occasions. The formats are illustrated in Fig. 3 and were: (1) words with conventionally oriented letters in their normal left-toright order; (2) words composed from mirrored letters but in conventional left-to-right order; (3) conventional letters in right-to-left order; and (4) mirrored letters in right-to-left order (i.e. true mirror script). The words were presented individually and her reading times were noted with a stopwatch. Alice's accuracy and reading times are shown in Table 2.

Once again, accuracy was high overall but differences between conditions were apparent in Alice's speed of responding, which was fastest for format 4 (true mirrored print) and slowest for format 1 (normal print). A comparison between left-to-right and right-to-left scanning with letter orientation held constant can be made by contrasting formats 1 and 3 (where the letters are in their conventional orientations) and formats 2 and 4 (where the letters are mirror reversed). The difference in the means favoured the right-to-left order in both cases, though it was only significant when the letters were mirror reversed ( 1 versus 3 : $t=0.87, \mathrm{NS} ; 2$ versus $4: t=2.43, P<0.025$ ). A comparison between normal and mirrored letters with scanning direction held constant can be made by contrasting formats 1 and 2 (where the scanning direction is left-to-right in both cases) and formats 3 and 4 (where the scanning direction is right-to-left). The difference in the means favoured the mirrored letters in both cases, though it was only significant when the scanning direction was right-to-left ( 1 versus 2 : $t=1.72$, NS; 3 versus $4: t=4.02, P<0.001$ ). 
Table 1. Alice's accuracy and reading times across a series of reading tests administered in conventional and mirror-reversed formats

\begin{tabular}{|c|c|c|c|c|}
\hline Test & Type & Orientation & Accuracy & Reading time \\
\hline Single letters & $\begin{array}{l}\text { Lower case } \\
\text { Lower case } \\
\text { Upper case } \\
\text { Upper case }\end{array}$ & $\begin{array}{l}\text { Conventional } \\
\text { Mirrored } \\
\text { Conventional } \\
\text { Mirrored }\end{array}$ & $\begin{array}{l}25 / 26 \\
22 / 26 \\
26 / 26 \\
26 / 26\end{array}$ & $\begin{array}{l}\text { Total }=59.5 \mathrm{~s} \\
\text { Total }=21.5 \mathrm{~s} \\
\text { Total }=21.0 \mathrm{~s} \\
\text { Total }=18.2 \mathrm{~s}\end{array}$ \\
\hline Syllable length ${ }^{\mathrm{a}}$ & $\begin{array}{l}\text { All words } \\
\text { All words }\end{array}$ & $\begin{array}{l}\text { Conventional } \\
\text { Mirrored }\end{array}$ & $\begin{array}{l}20 / 24 \\
20 / 24\end{array}$ & $\begin{array}{l}\text { Total }=8 \min 35 \mathrm{~s} \\
\text { Total }=2 \min 50 \mathrm{~s}\end{array}$ \\
\hline Reversible words & $\begin{array}{l}\text { All words } \\
\text { All words }\end{array}$ & $\begin{array}{l}\text { Conventional } \\
\text { Mirrored }\end{array}$ & $\begin{array}{l}21 / 24 \\
23 / 24\end{array}$ & $\begin{array}{l}\text { Mean }=3.4 \mathrm{~s} \\
\text { All }<1 \mathrm{~s}\end{array}$ \\
\hline $\begin{array}{l}\text { Imageability } x \\
\text { Frequency }\end{array}$ & $\begin{array}{l}\text { All words } \\
\text { All words }\end{array}$ & $\begin{array}{l}\text { Conventional } \\
\text { Mirrored }\end{array}$ & $\begin{array}{l}77 / 80 \\
76 / 80\end{array}$ & $\begin{array}{l}\text { Total }=10 \min 26 s \\
\text { Total }=5 \operatorname{min~} 4 \mathrm{~s}\end{array}$ \\
\hline Letter length & $\begin{array}{l}\text { Short } \\
\text { Short } \\
\text { Long } \\
\text { Long }\end{array}$ & $\begin{array}{l}\text { Conventional } \\
\text { Mirrored } \\
\text { Conventional } \\
\text { Mirrored }\end{array}$ & $\begin{array}{l}39 / 40 \\
38 / 40 \\
36 / 40 \\
40 / 40\end{array}$ & $\begin{array}{l}\text { Mean }=2.7 \mathrm{~s} \\
\text { Mean }=1.3 \mathrm{~s} \\
\text { Mean }=5.7 \mathrm{~s} \\
\text { Mean }=1.4 \mathrm{~s}\end{array}$ \\
\hline Lexical decision & $\begin{array}{l}\text { Words } \\
\text { Words } \\
\text { Non-words } \\
\text { Non-words }\end{array}$ & $\begin{array}{l}\text { Conventional } \\
\text { Mirrored } \\
\text { Conventional } \\
\text { Mirrored }\end{array}$ & $\begin{array}{l}29 / 30 \\
30 / 30 \\
26 / 30 \\
29 / 30\end{array}$ & $\begin{array}{l}\text { Mean }=7.1 \mathrm{~s} \\
\text { N/A } \\
\text { Mean }=22.4 \mathrm{~s} \\
\text { N/A }\end{array}$ \\
\hline $\begin{array}{l}\text { Word-to-picture } \\
\text { matching }\end{array}$ & $\begin{array}{l}\text { All items } \\
\text { All items }\end{array}$ & $\begin{array}{l}\text { Conventional } \\
\text { Mirrored }\end{array}$ & $\begin{array}{l}39 / 40 \\
37 / 40\end{array}$ & $\begin{array}{l}\text { Mean }=11.5 \mathrm{~s} \\
\text { Mean }=5.2 \mathrm{~s}\end{array}$ \\
\hline
\end{tabular}

aPALPA: Psycholinguistic Assessment of Language Processing in Aphasia (Kay et al., 1992).

Table 2. Alice's accuracy and reading times across two reading tests varying letter orientation and scanning direction (see Fig. 3 for examples of the different formats)

$\begin{array}{llll}\text { Letter order } & \text { Letter orientation } & \text { Accuracy } & \text { Reading time }\end{array}$

\begin{tabular}{|c|c|c|c|c|}
\hline \multicolumn{5}{|l|}{ Test 1} \\
\hline Format 2 & Left-right & Mirrored & $20 / 20$ & Mean $=2.9 \mathrm{~s}$ \\
\hline Format 3 & Right-left & Conventional & $19 / 20$ & Mean $=3.9 \mathrm{~s}$ \\
\hline Format 4 & Right-left & Mirrored & $20 / 20$ & Mean $=1.2 \mathrm{~s}$ \\
\hline Test 2 & & & & \\
\hline Format 5 & Vertical & Conventional & $20 / 20$ & Mean $=8.7 \mathrm{~s}$ \\
\hline Format 6 & Vertical & Mirrored & $20 / 20$ & Mean $=1.4 \mathrm{~s}$ \\
\hline
\end{tabular}

Another way to separate the effect of letter orientation from possible scanning biases is to print words with conventional or mirrored letters running vertically from top to bottom (formats 5 and 6 in Fig. 3). Alice read words in both formats accurately but showed a significant advantage in reading speed for mirrored over conventional letters $(t=11.2, P<0.001)$.

In sum, Alice's proficiency at mirrored reading would seem to be due to a combination of her being better at recognizing mirrored than normal letters, plus the fact that she is better at scanning in a right-to-left than in a left-toright direction. (Note that this scanning bias will affect the reading of text even more than the reading of individual words.)

\section{Mirror phenomena with non-verbal materials}

It is clear that Alice was a mirror reader (not a reverse reader) as well as being a mirror writer. Heilman $e t$ al. (1980) and Wade and Hart (1991) noted evidence of mirror phenomena for non-verbal materials in their patients. We tested this possibility by using a selection of non-verbal materials which have only one correct orientation.

Alice was tested first on Heilman et al.'s (1980) 'run-thebases' test. This requires the subject to draw a baseball field and mark the direction in which the players run. Although Alice demonstrated a good degree of knowledge of baseball in terms of the vocabulary used (e.g. referring without prompting to the 'plates'), she nevertheless numbered the bases in a clockwise fashion (the reverse of the correct orientation).

Such mirror reversal also applied to some country outlines. In one test Alice was asked to draw the shapes of seven different countries. Her drawings were not very good, but the orientation was discernible in six of the seven. Five of her drawings showed mirror-reversed orientation: the examples of Great Britain and Australia are shown in Fig. 4. Only one country (New Zealand) showed a correct left-right orientation. On another occasion Alice was asked to identify which of two silhouettes 


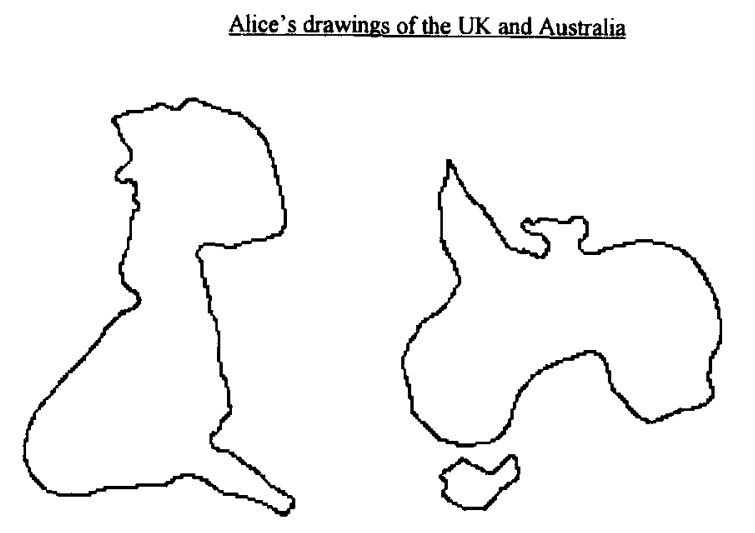

Alice's drawings mirror-reversed
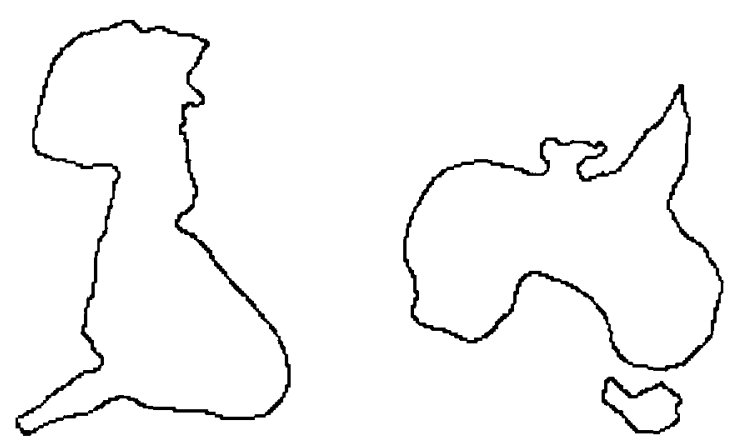

Fig. 4. Alice's drawings of Great Britain and Australia.

(correct and mirror-reversed) showed the correct outline for 12 different countries. Alice picked the correct version on only $4 / 12$ trials.

Alice was able to draw a clock face correctly together with Roman numerals. However, her reading of eight clock faces with the hands drawn in but no numerals showed consistent mirror reversal. She also consistently confused the short and long hands. Thus, when presented with a clock showing 3.00, she said that it showed 11.45, and a clock whose hands showed 11.00 was described as 12.10 .

Alice was also tested on 10 simple, asymmetrical geometric shapes (spirals, steps, etc.) previously used by Rodríguez et al. (1989) to search (unsuccessfully) for leftright reversals in the non-verbal domain in a mirror writer. Alice was asked to do three things with these shapes: (1) produce an immediate copy with the shape visible in front of her, (2) produce a copy after a 5-second exposure and a 5-second delay, and (3) select, after a 5-second delay, which of two shapes (the correct version and a mirrored version) matched a shape shown initially for $5 \mathrm{~s}$ (a twoalternative, forced-choice, delayed matching-to-sample test). In the immediate copying condition she made only minor errors on some of the shapes: all 10 were correctly oriented. In the delayed copying task, however, she reversed $9 / 10$ figures. In the delayed matching-to-sample test she scored 10/10 correct, but her comment was revealing: 'I know I get this wrong so I picked the opposite to the one I felt was correct'.

Alice was also given two tests of left-right orientation. The Benton et al. (1983) test was altered so that she could point to various named body parts of her own or the examiner's body using her left hand (given her right hemiplegia). She scored $8 / 8$ correct for body parts on herself but $0 / 8$ for the same parts on the examiner, each time choosing the opposite side. The Culver (1969) hand and feet test requires the subject to note whether pictured hands and feet are left or right. Alice found this test very difficult to complete, scoring $9 / 20$ (chance level $=10 / 20$ ). Similar problems with left and right on other bodies were reported by Feinberg and Jones (1985), Heilman et al. (1980) and Streifler and Hofman (1976) for their patients.

The results demonstrate that mirror phenomena were not limited to the verbal domain. Alice showed evidence of mirror reversals in any spatially coded stimuli that are specific for orientation, for example both words and country outlines. The experiments, including delayed copying and matching to sample, indicate that this reversal occurred for new material as well as for 'old' representations such as countries, words, etc. Like some other cases, Alice's mirror phenomena were accompanied by signs of left-right disorientation.

\section{Discussion}

Alice was a highly educated woman with no prior history of reading or writing problems who presented with mirror reading and mirror writing following a left CVA and progressive ischaemic attacks. She discovered her ability to mirror read quite by accident in 1994, though it is possible that the ability had lain unnoticed since 1992. Alice remained able to read conventional print quite accurately but was very slow compared to reading the same material in mirror fashion. Mirrored text appears to have suited her for two reasons. The first is that she was better at identifying mirrored letters than conventional letters, as shown by her speed of identifying single letters and her speed of reading vertically printed words which do not require leftright scanning. In addition, mirrored text runs right to left, and Alice showed better right-left than left-right scanning in other tasks (reporting rows of shapes and joining numbered circles). The advantage for mirrored over conventional presentation of words was shown in lexical decision and word-picture matching as well as in reading aloud. When reading mirrored words she showed no effect of letter length on reading speed, whereas a marked advantage for short over long words was observed for conventional format. This suggests that letter identification was a (virtually) parallel process for mirrored words and more of a serial process for conventional words. We suggest that the term 'mirror reading' should be reserved for superior reading of mirror-reversed than conventional text and that a tendency to read conventionally presented 
words and letters in right-to-left rather than left-to-right order should be referred to as 'reverse reading'.

Mirror phenomena were observed in a variety of nonverbal tasks. Alice numbered the baseball plates in reverse order. Five of six drawings of countries showed clear mirror reversal and when given the choice between the correct and mirrored silhouettes of countries she selected the mirrored version on eight out of 12 trials. When reading the time from a clock with hands but no numerals she consistently reversed left-right direction. Although she could copy an asymmetrical figure correctly when it was in front of her, she mirror reversed most figures when producing a copy after a delay. Given a choice between a correct and a mirrored version of a figure seen recently, she chose the correct versions but commented that she did this by selecting the opposite figure to the one she felt to be correct.

Very few, if any, patients like Alice have been reported before. Most mirror writers are unable to read their own written output, a few show reverse rather than mirror reading, and most do not show mirror phenomena on nonverbal tasks (Rodríguez et al., 1989). Heilman et al.'s (1980) patient was similar to Alice in that he mirror wrote and showed mirror reversal on some non-verbal tasks such as 'running the bases' and telephone dialling. Wade and Hart's (1991) case also shows similarities. This patient mirror wrote with her left (dominant) hand, though not with her right (non-dominant) hand, and produced a mirrored response on the 'running the bases' test. The main difference between Wade and Hart's (1991) patient and Alice is that the former's problems were either developmental or, at least, of early onset whereas Alice's were acquired in adulthood following normal development.

The patients of Heilman et al. (1980) and Wade and Hart (1991) may have differed from Alice in that they are reported as showing reverse reading rather than true mirror reading. Alice did not show reverse reading: she read conventional text slowly but did not reverse letter or word order, and she made no errors when reading conventionally formatted reversible words like GOD and SAW. We note, however, that it was only when Alice was asked to iron transfers onto $\mathrm{T}$-shirts that she discovered her facility for mirror reading. It could easily have gone unnoticed in her, and may remain unnoticed in others. For example, neither Heilman et al.'s (1980) patient nor Wade and Hart's (1991) patient seems to have been asked to read mirrored text, so we cannot be sure that they would not have performed well at true mirror reading. When Alice was tackling conventionally formatted words she showed an effect of letter length on reading speed which resembled that seen in letter-by-letter readers (Howard, 1991). How many letterby-letter readers have ever been asked to read mirrored words?

Even when Alice's ability to mirror read was noticed, it may well not have come to the attention of a speech and language therapist or a neuropsychologist who would be alert to the potential significance of the phenomenon. Neuropsychologists grow used to the experience of talking about a supposedly rare phenomenon to groups of people who deal with neurological patients on a regular basis, only to be approached by a member of the audience who announces that she saw someone just like that last week! We would be cautious in assuming that because there have been very few reports of patients like Alice, her condition is an extremely rare one.

Alice's neurological condition does not seem particularly unusual, so if her symptomatology should prove to be as rare as the literature suggests, then a possible explanation might be that she had an abnormal pattern of premorbid brain organization. The only hint of this that we can point to is that she became dysprosodic following her stroke, her speech being flat and monotonous, and that dysprosody is usually associated with right rather than left hemisphere brain injury (Ross, 1981). It may be significant that Streifler and Hofman (1976) and Wade and Hart (1991) also noted the presence of aprosodia in their patients.

\section{Explaining Alice's mirror phenomena}

We noted in the Introduction that mirror writing is the most widely reported and discussed mirror phenomenon in the neuropsychological literature. Most theories of mirror writing assume that the underlying representations of letter shapes remain normal but that they emerge the wrong way round because motor programmes appropriate to the dominant writing hand are used to control the nondominant hand (e.g. Buxbaum et al., 1993; Ellis, 1988). One could offer an analogous account of mirror reading which posited mirror reversal of representations at input rather than at output. If the spatial descriptions of written words were subject to a mirror reversal during perception, then the format which would continue to match correctly oriented internal representations would be mirrored words (because they would be transformed back to the correct orientation). Hence, spatial reversal of representations at input would favour mirrored text over conventional text. One could even extend this line of theorizing into the nonverbal domain: normal internal representations subject to mirror transformation at output would emerge mirror reversed, as in Alice's drawings of Britain and Australia, while representations mirrored at input would need to be presented in already mirrored format if they were to match against stored, correct representations.

The notion of normal central representations with mirror reversal at input and output would not, however, seem to account for all of Alice's symptoms. In particular, if representations were reversed at both input and output, then delayed copying of patterns should be intact, because double reversal should result in correct reproduction of a seen pattern. Alice, in contrast, reversed nine out of 10 asymmetrical patterns after a delay of just $5 \mathrm{~s}$. This is 
more compatible with the notion that she had formed mirror-reversed representations of the patterns when they were visible, and that those mirror-reversed representations controlled the later act of reproduction.

The explanation we wish to propose for Alice's pattern of symptoms is highly speculative. We begin with the observation that natural kinds are seldom, if ever, distinguished by their left-right orientation. If you wish to test a patient on the ability to make differential responses to mirror-reversed forms, then you are obliged to use artefacts such as letters and clock faces. In Nature, if one object is identical to another, but left-right reversed, then it is the same thing moving in the opposite direction or viewed from the other side. Suppose that your first encounter with a tiger is the sight of one walking left to right across your field of view. When, shortly afterwards, you see a tiger walking right to left it would seem sensible for your perceptual system to treat that mirror-reversed image as the same thing (or at least, another member of the same class of things which require to be responded to in the same way). One way to do this would be to form an abstract threedimensional representation of the object which could generalize between one view and another (it should be noted that similar explanations have been presented for other patients with left-right coding deficits, e.g. Riddoch and Humphreys, 1988, pp. 312-14; Turnbull and McCarthy, 1996, pp.70-1). It has been argued, however, that we do not recognize objects from different viewpoints by storing abstract three-dimensional representations, but rather by storing a selection of different twodimensional views (see Perrett et al., 1994, for a review). If this is the case, it would make good adaptive sense if the perceptual system, on seeing an object from one viewpoint, was able to extrapolate and create other view-specific representations which could mediate later recognition of the object from other perspectives; for example, creating mirror-reversed representations in addition to veridical representations of seen objects.

Corballis and Beale (1976, p. 189) suggested that homotopic connections between the two hemispheres might allow the creation of a veridical representation in one hemisphere and a mirror-reversed representation in the other. Heilman et al. (1980) discussed the application of this concept to mirror phenomena in human neuropsychology. They noted that learning to read is a situation where mirror engrams cannot be used to aid recognition, because a child must learn to treat $b$ and $d$, and $p$ and $q$, as different things rather than the same thing seen from a different viewpoint. Such letter pairs create problems for children learning to read who may tend for a while to produce mirror-reversed letters in their writing. Perhaps learning to read and write involves learning to inhibit access to mirror engrams of letter forms which nevertheless continue to exist in the brain along with mirror engrams of non-verbal stimuli. If so, mirror writing might arise in some cases when writing is controlled by the mirror rather than the veridical representations of letter shapes, and mirror reading might arise when letter and word recognition is mediated by mirror rather than reverse engrams.

Alice could read and write conventional text, but both were very slow, and her reading of conventional words seemed to involve serial letter identification. One could argue that her reading and writing of words in conventional formats was mediated by mirror engrams and that reading conventional text involved mentally reversing letters in perception while writing involved reversing letters in production. It is also possible, however, that reading and writing of words in conventional formats was mediated by the longstanding veridical representations but that using them had become very difficult. As we have already noted, Alice's right-to-left scanning preference would also favour reading and writing mirrored rather than conventional text.

Can Alice's performance on non-verbal tasks tell us whether she only retained the use of mirror engrams or had access to both mirror and veridical engrams with perhaps a bias towards using the former? There are clear examples of her using mirrored non-verbal representations, as for example in her numbering of baseball bases and her drawings of Britain and Australia. She also mirror-reversed on all eight clock-reading trials. But she drew New Zealand correctly and recognized $4 / 12$ correct shapes in delayed matching to sample. It is possible that she retained both mirrored and veridical representations in the non-verbal domain, but she tended to favour the mirrored over the veridical forms. The left-right confusion which Alice demonstrated in some situations, which has been observed in other patients showing mirror phenomena, might be related to an impairment in selecting between veridical and mirror engrams, and suppressing mirror engrams where necessary (as in reading and writing), which could be one of the functions of the dominant parietal lobe.

\section{Acknowledgements}

We thank 'Alice' for her patience and her willingness to complete hours of testing. We are grateful to Dr A. Gholkar for his analysis of the CT scans. We would like to thank Ian Robertson and an anonymous reviewer for their useful comments on a previous draft of this paper. This work was completed while M.A.L.R. was supported by the Engineering and Physical Science Research Council.

\section{References}

Benton AL, Hamsher KdeS, Varney NR, Spreen O. Body-schema disturbances: right-left orientation and finger localization. In: Heilman KM, Valenstein E, editors. Clinical neuropsychology. New York: Oxford University Press, 1983.

Bramwell B. Mirror reading and mirror writing in a left-handed boy who suffered from epileptic fits. Clinical Studies 1909; 8: 370.

Buxbaum LJ, Coslett HB, Schall RR, Goldberg G. Hemispatial determinants in mirror writing. Journal of Clinical and Experimental Neuropsychology 1993; 15: 43 . 
Chan JL. Ross ED. Left-handed mirror writing following right anterior cerebral-artery infarction: evidence for nonmirror transformation of motor programs by right supplementary motor area. Neurology 1988; 38: $59-83$.

Corballis MC, Beale IL. The psychology of left and right. New Jersey: Lawrence Erlbaum Associates, 1976.

Corballis MC. Beale IL. The ambivalent mind: the psychology of left and right. Chicago: Nelson-Hall, 1983.

Critchley M. Mirror-writing. London: Kegan Paul, Trench, Trubner \& Co. Ltd, 1928.

Culver CM. Test of right-left discrimination. Perceptual and Motor Skills 1969; 29: 863-7.

Downey JE. On the reading and writing of mirror-script. Psychological Review 1914; 21: 408-41.

Ellis AW. Normal writing processes and peripheral acquired dysgraphias. Language and Cognitive Processes 1988; 3: 99-127.

Feinberg T, Jones G. Object reversals after parietal lobe infarction a case report. Cortex 1985; 21:261-71.

Heilman KM, Howell G, Valenstein E, Rothi L. Mirror-reading and writing in association with right-left spatial disorientation. Journal of Neurology, Neurosurgery and Psychiatry 1980; 43: 774-80.

Howard D. Letter-by-letter readers: evidence for parallel processing. In: Besner D, Humphreys GW, editors. Basic processes in reading: visual word recognition. Hillsdale, NJ: Lawrence Erlbaum Associates, 1991.

Kaplan E, Goodglass H, Weintraub S. The Boston Naming Test. Boston: Veteran's Administration, 1976.

Kay J, Lesser R, Coltheart M. PALPA: Psycholinguistic Assessments of Language Processing in Aphasia. Hove: Lawrence Erlbaum, 1992.

Kucera $H$, Francis WN. A computational analysis of present day American English. Providence, RI: Brown University Press, 1967.

Perrett DI, Oram MW, Hietanen JK, Benson PJ. Issues of representation in object vision. In: Farah MJ, Ratcliff $G$, editors. The neuropsychology of high-level vision. Hillsdale, NJ: Lawrence Erlbaum, 1994: 33-61.

Quinlan PT. The MRC Psycholinguistic Database. London: Oxford University Press, 1992.

Riddoch MJ, Humphreys GW. Description of a left/right coding deficit in a case of constructional apraxia. Cognitive Neuropsychology 1988; 5: 289-315.

Rodríguez R, Aguilar M, González G. Left non-dominant hand mirror writing. Brain and Language 1989; 37: 122-44.

Ross ED. The aprosodias. Archives of Neurology 1981; 38: 561 -9.

Streifler M, Hofman S. Sinistrad mirror writing and reading after brain concussion in a bi-systemic (oriento-occidental) polyglot. Cortex 1976; 12: 356-64.

Turnbull $\mathrm{OH}$, McCarthy RA. Failure to discriminate between mirrorimage objects: a case of viewpoint-independent object recognition? Neurocase 1996; 2: 63-72.

Wade JB, Hart RP. Mirror phenomena in language and nonverbal activities - a case report. Journal of Clinical and Experimental Neuropsychology 1991; 13: 299-308.

Received on 21 November, 1996; resubmitted on 15 January, 1997; accepted on 28 January, 1997

\section{Life in a mirrored world: report of a case showing mirror reversal in reading and writing and for non-verbal materials}

\author{
M. A. Lambon Ralph, C. Jarvis \\ and A.W. Ellis
}

\begin{abstract}
We report a single case study of a patient 'Alice' who, following a series of ischaemic attacks, became a mirror reader and mirror writer. Alice read mirror-reversed words much more efficiently than conventionally presented items. Additional tests revealed a mirror reversal of many nonverbal, spatial representations including clock faces, geometric figures and country outlines. Although Alice showed more efficient right-left than left-right scanning, this scanning bias was not able to account for all her mirror symptoms. Possible theoretical interpretations of Alice's pattern of symptoms are discussed.
\end{abstract}

Journal

Neurocase 1997; 3: 249-58

\section{Neurocase Reference Number}

O81

Primary diagnosis of interest

Mirror reading, writing and other mirror phenomena

\section{Author's designation of case}

Alice

\section{Key theoretical issue}

- The nature and characteristics of mirror reading and its relationship to other mirror phenomena

Key words: mirror reading; mirror writing; left-right disorientation

\section{Scan, EEG and related measures}

CT scans from 1992 and 1994

\section{Standardized assessment}

Boston Naming Test, Culver's hand and feet test

\section{Other assessment}

Detailed assessment of mirror reading and for the presence of mirror phenomena in non-verbal tasks

\section{Lesion location}

- Focal areas of acute infarction in the left basal ganglia and posterior temporal region, in the vascular territory of the left middle cerebral artery plus significant atrophy of the left temporal-parietal region associated with dilation of the left lateral ventricle and cortical sulci

\section{Lesion type}

CVA plus progressive ischaemia

\section{Language}

English 